\title{
U⿱宀⿻三丨口
}

\section{Concepts for communication about risk in dementia care: A review of the literature}

Stevenson, M., McDowell, M., \& Taylor, B. (2018). Concepts for communication about risk in dementia care: A review of the literature. Dementia, 17(3), 359-390. https://doi.org/10.1177/1471301216647542

Link to publication record in Ulster University Research Portal

\section{Published in:}

Dementia

Publication Status:

Published (in print/issue): 01/04/2018

DOI:

$10.1177 / 1471301216647542$

\section{Document Version}

Author Accepted version

\section{General rights}

Copyright for the publications made accessible via Ulster University's Research Portal is retained by the author(s) and / or other copyright owners and it is a condition of accessing these publications that users recognise and abide by the legal requirements associated with these rights.

\section{Take down policy}

The Research Portal is Ulster University's institutional repository that provides access to Ulster's research outputs. Every effort has been made to ensure that content in the Research Portal does not infringe any person's rights, or applicable UK laws. If you discover content in the Research Portal that you believe breaches copyright or violates any law, please contact pure-support@ulster.ac.uk. 
Stevenson, M., McDowell, M. E. and Taylor, B. J. 'Concepts for communication about risk in dementia care: A review of the literature', Dementia: The International Journal of Social Research and Practice Advance Access published May 13 2016, doi: 10.1177/1471301216647542

\section{Concepts for communication about risk in dementia care: A review of the literature}

Stevenson, M., McDowell, M. E. and Taylor, B. J. 'Concepts for communication about risk in dementia care: A review of the literature', Dementia: The International Journal of Social Research and Practice Advance Access published May 13 2016, doi: $10.1177 / 1471301216647542$

\section{Mabel Stevenson}

School of Sociology \& Applied Social Studies, Ulster University, Northern Ireland

\section{Michelle E McDowell}

Harding Centre for Risk Literacy, Max Planck Institute Berlin, Germany

\section{Brian J Taylor ${ }^{1}$}

School of Sociology \& Applied Social Studies, Ulster University, Northern Ireland

\section{Abstract}

Communication about risk is central to decisions in dementia care. This review synthesises research on risk concepts and communication in dementia. Twelve bibliographic databases and one online search engine were searched up to February 2016. Reference lists of two related literature reviews were used. Thirty-four papers were identified that focused on risk concepts; two papers related to risk communication. Concepts were often socially constructed, and perceptions may differ from actual adverse outcomes. Perceptions of risk and thresholds of risk-tolerance varied between individuals with dementia, carers and professionals. Individuals with dementia were found to behave differently from controls when making decisions involving risk information in experimental settings. Cognitive impairment was also associated with lower health numeracy. These findings highlight the importance of communication between stakeholders when making decisions and of presenting information in an appropriate way to support informed and positive risk taking. Research is required on risk communication in dementia.

\section{Keywords}

Dementia, literature review, risk communication, risk concepts, risk taking

\section{Introduction}

Globally there are an estimated 46 million people living with dementia with this figure projected to increase to 131.5 million by 2050 (Prince et al., 2015). Global population ageing and the associated increase in prevalence of dementia (Sosa-Ortiz, Acosta-Castillo, \& Prince, 2012) present a major international health and policy issue (Wortmann, 2012) with global economic and societal impacts (Wimo, Winblad, \& Jönsson, 2010; Wimo et al., 2013; Prince et al., 2015). Determining appropriate health and social care for people with dementia is therefore paramount for future health policy initiatives. Understanding how the risks experienced by people living with dementia are conceptualised and communicated by individuals, family members and professionals will be integral in informing such initiatives.

Dementia is an umbrella term referring to a group of diseases and conditions that may affect a range of cognitive and emotional functions. These can include memory, orientation, comprehension, calculation and judgement as well as changes in mood, emotional control or

\footnotetext{
${ }^{1}$ Corresponding author: Brian Taylor, School of Sociology \& Applied Social Studies, Ulster University, Magee Campus, Derry, BT48 7JL, UK. Email: bj.taylor@ulster.ac.uk
} 
Stevenson, M., McDowell, M. E. and Taylor, B. J. 'Concepts for communication about risk in dementia care: A review of the literature', Dementia: The International Journal of Social Research and Practice Advance Access published May 13 2016, doi: 10.1177/1471301216647542

behaviour, and challenges with activities of daily living (Alzheimer's Society, 2014; World Health Organisation, 1993; 2015). Importantly, these changes can make an individual more susceptible to risks of daily life, such as falls (Kröpelin, Neyens, Halfens, Kempen, \& Hamers, 2013; Muir, Gopaul, \& Odasso, 2012); risks associated with driving (Adler, Rottunda, \& Dysken, 2005; Flanagan, 2011) or walking about (often referred to as 'wandering') (Cipriani, Lucetti, Nuti, \& Danti, 2014; Douglas, Letts, \& Richardson, 2011); mismanagement of medication (Douglas et al., 2011; While, Duane, Beanland, \& Koch, 2013); increased vulnerability to abuse (Compton, Flanagan, \& Gregg, 1997; Selwood \& Cooper, 2009) as well as psychological risks such as loneliness (Holmen, Ericsson, \& Winblad, 1999; Moyle, Kellett, Ballantyne, \& Gracia, 2011) and loss of identity (Caddell \& Clare, 2010). As the progression of dementia is highly unique, these risks will vary according to individual circumstances and availability of support systems. Decisions relating to health and social care in dementia often involve dealing with risks, making good communication and an understanding of the meaning of risk to different stakeholders of core importance. While studies relating to more general aspects of understanding and improving communication between healthcare providers and people with dementia are of relevance (Adams \& Gardiner, 2005; Österholm \& Hydén, 2014), research specifically focused on the communication of risk information between professionals, people with dementia and family carers is necessary to inform this particular area of health and social care.

\section{Risk concepts and risk communication}

The range of potential physical and psychological risks faced by people with dementia means that these individuals and their families are often faced with care decisions involving risks. For example, the decision whether or not to use assistive technology or to take a particular medication. Clear and transparent communication of information about risks is an important condition for such decision making, particularly given an increased focus on autonomy and informed decision making not only in dementia care (Alzheimer Europe, 2009; Fetherstonhaugh, Tarzia, \& Nay, 2013) but in healthcare more generally (Stacey et al., 2014). For the purposes of this review, risk communication is defined as the exchange of information between individuals receiving services, family members and professionals about possible harm and potential benefits in client situations and care options, so as to inform decision making about care (cf. Taylor, 2013). The practice of good risk communication should be a shared process involving the patient and carer, and should aim to facilitate informed choice (Bodemer \& Gaissmaier, 2012, p625; Edwards \& Elwyn, 2001). Of core importance to this process are person-centred approaches built on a relationship and dialogue between the individual and health professional (Alaszewski, 2005). While there exists a substantial and expanding body of literature on risk communication in health care, research on risk communication in dementia care is less developed. To address this gap, the current paper aims to synthesis work on risk communication in dementia care to better inform practice in this field.

A related issue integral to effective risk communication is an understanding of what constitutes a risk to different stakeholders. This matter is even more crucial in the context of dementia care owing to the many different stakeholders involved in decisions involving risks (e.g., family carers, professionals, and the individuals with dementia themselves). For instance, in order to communicate risks, individuals must first develop ideas about risks including identifying which scenarios they define as risky; which risks they find to be most concerning; and deciding on preferred approaches to the risks based on these concepts. Similarly the manner in which information about risks is communicated may also shape conceptualisations by enabling individuals to understand risk outcomes more accurately, including likelihood of risks, and by facilitating understanding of alternative perspectives. There is no standard definition of 'risk' in relation to dementia care. One approach to understand the multiple meanings of risk for different stakeholders across situations (Clarke, Wilkinson, Keady, \& Gibb (2011a)), is to analyse how risk is discussed in the literature. 
Stevenson, M., McDowell, M. E. and Taylor, B. J. 'Concepts for communication about risk in dementia care: A review of the literature', Dementia: The International Journal of Social Research and Practice Advance Access published May 13 2016, doi: 10.1177/1471301216647542

Risk is often understood as a numeric concept representing a quantification of the probability of an event (Lupton, 1999, p7) and is frequently associated in contemporary society with negative terms such as hazard, harm and loss (Lupton, 1999, p8). However, quantifying risks experienced by individuals with dementia is challenging given that many risk outcomes (e.g., minor home accidents, or getting lost) are unlikely to be documented or are difficult to recognise and record (e.g., psychological risks). Further, depending on the perspective, risks can be conceived as both negative and positive, and risk-taking can enable many beneficial outcomes (Manthorpe \& Moriarty, 2010; Morgan, 2004; Morgan \& Williamson, 2014). The lack of a clear definition of risk, the multiplicity of perspectives, and an absence of a quantifiable knowledge base from which to extrapolate likelihood for many risks makes risk communication in this domain problematic. Exploration of these multiple meanings and perspectives of risk from the literature and understanding how these risks are constructed may therefore better inform the risk communication process. An examination of underlying concepts and approaches towards dealing with risk can facilitate our understanding of how stakeholders manage risks and the processes that inform these approaches.

\section{Previous studies on risk concepts in dementia care}

Risk concepts have been investigated in prior work on dementia care, however, the focus of this work has centred on the assessment and management of risk (Thom \& Blair, 1998) and on understanding risk and resilience in dementia (Bailey et al., 2013). Thom and Blair (1998) synthesised findings from 19 publications (including journal articles, research papers, books and publications from voluntary organisations) and identified contrasting approaches towards risks across different professional groups. Both risk-averse attitudes that focused primarily on the carer's perspective and more comprehensive, balanced approaches factoring into account the rights and views of the individual with dementia were found to be evident. The authors established that there was a paucity of research on self-assessment and management of risk from the perspective of people with dementia. Although the authors attempted to gather statistical evidence on the prevalence of various risks, the data was found to be limited and inconclusive. As the current paper focused on risk communication and risk concepts more broadly, no papers included in the review by Thom and Blair (1998) were retrieved in the current search, although one additional paper was extracted from the reference list. Further, since their publication, a substantial body of literature exploring the experiences and perspectives of people with dementia, carers, and professionals has developed.

More recently, Bailey et al. (2013) reviewed literature on risk, resilience and dementia and included findings from UK Government documents and reports in addition to peer-reviewed publications. Four key dimensions of risk and resilience were identified: risk and resilience across the lifespan; risky and resilient life with dementia; multiple narratives; and the significance of people and place. The review established the significance of local community in managing risks to people with dementia, owing to the enduring knowledge of the individual and a willingness to support them. Although the theme of resilience was less relevant to the current synthesis, seven of the papers included in Bailey et al. (2013) were identified through the current search, and one additional paper was sourced from the reference list of that previous review.

The current synthesis incorporates 25 papers not included in either of the previous reviews and analyses perceptions and constructions of risk, as well as approaches towards risk, with a focus on how these concepts may inform understanding of risk communication. The authors also set out to retrieve papers with a specific emphasis on risk communication in dementia care, a theme that was not explored in these previous reviews. The aim of this paper therefore is to synthesise findings of studies on risk concepts in dementia care (including differing perceptions and approaches) with a particular focus on the issues and challenges in risk communication. 
Stevenson, M., McDowell, M. E. and Taylor, B. J. 'Concepts for communication about risk in dementia care: A review of the literature', Dementia: The International Journal of Social Research and Practice Advance Access published May 13 2016, doi: 10.1177/1471301216647542

\section{Literature search strategy}

A systematic search of literature on risk and dementia care was performed across twelve bibliographic databases (Applied Social Sciences Index and Abstracts (ASSIA), Campbell Collaboration, Cumulative Index to Nursing and Allied Health (CINAHL), Cochrane Library, Communication Abstracts by EBSCO, Medline, PsycINFO, Scopus, Social Care Online, Social Sciences Citation Index (SSCI), Social Services Abstracts and Trip) and an online search engine (Google Scholar). Combinations of "risk" and "dementia" concept groups were applied. Search terms included: risk communication, risk management, risk assessment, risk perception, risk concepts, attitudes to risk, ideas about risk, risk taking, risk enablement, dementia and Alzheimer's. All studies published up until and including December, 2013 were examined. Reference lists of relevant literature reviews retrieved via the database search were also inspected. The database search was later updated to include papers published up to 23 February 2016. Papers identified by subsequent contact with experts were also then added to the review.

To be included in the review studies had to be: empirical studies; focus on risk communication or risk concepts in dementia; be published in a peer-reviewed journal; and be available full text in English. Policy, case law, theoretical and ideological papers were excluded. Papers were included if they addressed topics of risk communication or risk concepts in dementia care, and examined either individuals with dementia, carers or family members of people with dementia, or health and social care professionals. Studies examining risks of developing dementia or exploring risks associated with caring for an individual with dementia were excluded.

Of the 3608 papers retrieved from the initial search, 209 were considered potentially relevant after removing duplicates and scanning abstracts. Twenty-nine articles met the inclusion criteria. Two additional articles were identified from the reference lists. Following the updated database search and contact with experts, five additional papers were added resulting in a total of 36 papers included in the review. The Preferred Reporting Items for Systematic Reviews and Meta-Analyses (PRISMA) 2009 checklist was used as a tool to inform data extraction. For a more detailed overview of the search methodology, please refer to Stevenson, Taylor and Knox (in press).

\section{Findings}

Data extracted included country and year of publication, participant information (including demographic information, if available) method of data collection, method of analysis, types of risks identified, risk or protective factors specified and themes relating to risk concepts or risk communication. Data is summarised in the table below:

\section{$<$ TABLE 1>}

\section{Risk concepts}

Findings were categorised according to four recurring themes in the literature: (1) types of risk identified, and whether these risks extended beyond concepts of physical safety risks to acknowledge also psychosocial risks; (2) perceptions and constructions of risk including social constructions of risk, perceptions of risk (and protective) factors, congruence of risk perceptions with reality and the concept of care crises in risk; (3) approaches to dealing with risk including acceptable risk taking and risk tolerance versus risk aversion; and (4) decision making involving risk by individuals with dementia that tended to focus on experimental studies analysing whether cognitive processes and emotional responses impaired decision making 
Stevenson, M., McDowell, M. E. and Taylor, B. J. 'Concepts for communication about risk in dementia care: A review of the literature', Dementia: The International Journal of Social Research and Practice Advance Access published May 13 2016, doi: 10.1177/1471301216647542

behaviour of participants with dementia, specifically in the domain of risk. Potential implications for the process of risk communication across these four themes are suggested.

\section{Types of risks}

Developing an understanding of the matters that are frequently conceptualised as 'risky' for people living with dementia is important in order to identify the types of situations that will involve communications about risks. Although psychosocial risks (risks to mental and emotional wellbeing) were mentioned in several papers, the predominant focus of the majority of papers was on physical safety risks (potential for accident or injury). Importantly, the concept of what constituted a risk varied across study groups. Themes that were referred to as risks or safety issues in the primary research element of the papers are included in Table 1.

The most prominent risks identified in the literature could be categorised as risks to physical safety such as falls or medications management. Psychosocial risks were recognised in several papers in relation to themes including depression, family life, independence, institutionalisation, loneliness, personhood and self-esteem. Notably these psychosocial themes were referenced in five of the papers gathering data on individuals with dementia, two gathering data on family carers and two of the papers gathering data on professionals.

Consistent with the findings from previous reviews (Thom \& Blair, 1998; Bailey et al., 2013), several of the papers drew attention to how groups conceptualised risk in different ways with respect to the situations or behaviours they perceived as risky. Gilmour, Gibson, and Campbell (2003) found that different professional groups tended to emphasise different risks with social workers most likely to identify risks similar to those of concern to family members. Robinson et al. (2007) discussed the concept of plural constructions of risk where the same risk, for example wandering, was conceptualised and managed in different ways. In some instances the activity was perceived as risky with an emphasis on prevention of harm while an activity might also be conceptualised as positive with respect to the benefits to health and wellbeing. Variability in the construction of risk from the perspective of people with dementia, caregivers and professionals was also reported in papers by Clarke (2000) and Clarke et al. (2009; 2010; 2011b).

\section{Perceptions and constructions of risks}

Risk communication involves seeking a shared understanding of different perspectives of risk. Accordingly, how risks are perceived will undoubtedly affect attitudes and approaches towards these risks. When it came to how groups perceived and constructed risk, three main aspects were discussed. The section begins by first analysing social constructions of risk and by distinguishing risk factors that were identified in the literature as those interpreted to stem from the individual's dementia and those formed within the environment. The paper then looks at whether perceptions of risk factors are congruent with actual outcomes and whether there is a tendency to over or underestimate the risks perceived by different groups. Finally the concept of crises in risk is examined, as often approaches to risk are formed and decisions are made during this stage.

Social construction of risk. Concepts of risk were interpreted in several papers as being socially constructed via a variety of influences. In particular, a distinction was observed between perceptions of risk factors that could be interpreted as rooted within the individual's dementia experience and those that could be categorised as deriving from the environment. Social constructions of risk were influenced by: 
Stevenson, M., McDowell, M. E. and Taylor, B. J. 'Concepts for communication about risk in dementia care: A review of the literature', Dementia: The International Journal of Social Research and Practice Advance Access published May 13 2016, doi: 10.1177/1471301216647542

a) Acquired knowledge, with professionals more likely to assess and manage risk based on their medical knowledge and prior experience in their field whereas family carers were influenced by their knowledge of the person (Clarke, 2000);

b) discursive processes between professionals and family carers where risks were jointly constructed, assessed and managed through conversational exchanges (Adams, 2001);

c) stereotyped or gendered constructions of risk behaviours held by professionals included the idea of males presenting as more aggressive in contrast to the "sweet old lady" with dementia (Beattie, Daker-White, Gilliard, \& Means, 2005); and

d) the construction of meaning within the social context of everyday experiences of people with dementia, including the benefits of various social behaviours or activities that justified engagement in potentially 'risky' activities (Clarke et al., 2010).

Stakeholders perceived various factors as increasing the likelihood of outcomes relating to either physical safety or psychosocial risks (Table 1; column five). Several of these risk factors could be conceptualised as stemming from the individual's dementia, for example changing abilities, difficulty with recall and lack of insight or judgement (Bond, Corner, Lilley, \& Ellwood, 2002; Clarke et al., 2009; Cott \& Tierney, 2013; Johansson, Bachrach-Lindström, Struksnes, \& Hedelin, 2009; Oyebode, Bradley, \& Allen, 2013; Sandberg, Rosenberg, Sandman, \& Borell, 2015; Watts, Cassel, \& Howell, 1989; Waugh, 2009). Alternatively risks were also perceived as relating to external risk or protective factors that could be located outside of the individual including the environmental (both hazards and supports), risks from strangers, levels of support (both formal and informal), caregiver skills and knowledge of dementia and safety matters, levels of supervision (including informal community surveillance), history of safety incidents and risks from society and systems (Buri \& Dawson, 2000; Cott \& Tierney, 2013; Gilmour et al., 2003; Harris, 2006; Horvath et al., 2005; Johansson et al., 2009; Lach, 1995; Morgan, 2009; Robinson et al., 2007; Sandberg et al., 2015; Tsunaka \& Chung, 2012; Walker, Livingston, Cooper, Katona, \& Kitchen, 2006; Watts, Cassel, \& Howell, 1989; Waugh, 2009). Risks were also associated with continued engagement in everyday home or leisure activities for example running, socialising or domestic tasks (Bond et al., 2012; Clarke et al., 2009 \& 2010; Tsunaka \& Chung, 2012).

Congruence of risk perceptions and reality. Acknowledging the congruence between perceptions of risk and actual outcomes can have important implications for approaches to dealing with and communicating about risk. Overestimating risks may result in unnecessarily risk aversive approaches while underestimations may result in individuals being placed at increased harm. Awareness of misperceptions is important to support communications that address these possible misinterpretations. A number of quantitative papers suggested that the congruence between judgements made by caregivers and professionals as to factors presumed to increase risk for people with dementia were not always significantly related to risk outcomes when measured. Further, people with dementia may even overestimate typical non-threatening situations. Accordingly, clarifying what an individual perceives to be a risk and determining how risky different behaviours actually are is important for the risk communication process.

A small number of quantitative studies examined associations between perceived risk factors and specific, measurable risk outcomes. Lach, Reed, Smith, and Carr (1995) explored caregiver safety concerns in relation to dementia severity and found that stage of dementia (categorised as either questionable/mild or moderate/severe) was not significantly associated with engagement in unsafe behaviours or number of reported accidents. Rather, unsafe behaviour was related to having had an accident in the previous year and further, none of these accidents resulted in more than minor injury or substantial damage to property, implying that these accidents were not serious. The study reported that carers were more likely to apply safety precautions for care recipients in the moderate to severe group which indicates greater levels of concern when caring for a person with more advanced dementia. However these 
Stevenson, M., McDowell, M. E. and Taylor, B. J. 'Concepts for communication about risk in dementia care: A review of the literature', Dementia: The International Journal of Social Research and Practice Advance Access published May 13 2016, doi: 10.1177/1471301216647542

preventative measures themselves may have led to reduction in risky behaviours and accidents, therefore acting as a moderating factor. Similarly to some of the findings above, in a qualitative study Gilmour et al. (2003) reported that no caregivers, professionals or people with dementia reported any major incidents of harm in respect to a group of ten people with dementia living alone. Notably these individuals were all known to services (nine received care packages) and had daily contact from either family, care staff or neighbours. Another study measuring caregiver perception of risk, (Walker et al., 2006) found that family carers generally perceived it to be unsafe to leave a person with dementia (whether mild, moderate or severe) alone and $68.5 \%$ of these caregivers reported at least one incident that had considerably compromised the safety of their care recipient in the previous year. Findings showed that the greater the frequency of risk incidents, the greater the worry about leaving the care recipient alone. No significant relationship was however found between the number of hours the caregiver thought the care recipient should be left alone (a measure of perceived risk) and the number of incidents that had compromised the care recipient's safety over the previous year. Tuokko, MacCourt, and Heath (1999) in a study involving review of client records, found that while individuals living alone in the community were regarded by clinicians as being at increased risk in relation to some hazards in the home (nutrition, medication management, hygiene, fire and falls), they did not die earlier and were not placed within care facilities sooner than those living with a spouse. The findings suggest that these service users were not at markedly greater risk in the community. However, the authors did note that the sample involved only those who were accessing services and that the study did not report other outcomes including hospitalization or financial abuse from records. Together, these findings suggest that perceptions of risk factors by carers and professionals do not always correspond with actual quantified risks of adverse outcomes in the ways expected.

Perceptions of risk were in one study found to differ between individuals with varying stages of cognitive impairment and their peers without dementia. Henry et al. (2009) compared perceptions of threat by individuals with Mild Cognitive Impairment $(\mathrm{MCl})$ and early stage dementia to age matched controls. Participants provided danger ratings for faces or situations considered to present low or high threat. Although all participants were able to differentiate appropriately between high and low threat facial expressions, people with dementia attributed greater levels of danger to typically non-threatening situations. The authors argue that for individuals with dementia such judgements may be rational given that low danger situations may present greater risk to these individuals than to the general population, and underestimating high threat situations would be of greater concern. Further, the results suggest that these differences were related to declines in cognitive functioning.

Care crises and risk. Communications and decisions about risks often take place during times of crisis. Risk was in some cases experienced as a critical life stage or event requiring a decision by carers. These decisions involved judgements regarding the tolerability of specific (and cumulative) risks and application of strategies to help balance the risks. Both cognitive and environmental changes were found to signal crises to carers. The concept of 'crisis' in risk was a distinct element in four of the papers reviewed (Buri \& Dawson, 2000; Cott \& Tierney, 2013; Ledgerd et al., 2015; Waugh, 2009). Buri and Dawson (2000) in their study on coping with falls risk refer to the idea of carers treading a precarious line between order and chaos while making attempts to either maintain or recreate order in their family life by applying various strategies to reduce the risk. Waugh (2009) refers to the idea of 'critical times' as identified by community care practitioners as placing the individual who lived alone as more at risk including decline in physical health and functional skills, withdrawal of support and diminishing community tolerance. It was recognised that the interaction between multiple crises often resulted in the individual being assessed as unsafe to live at home. This idea of cumulative risk factors is referenced also in the paper by Cott and Tierney (2013) who use a model of 'red flags' signalling behaviours or changes in behaviour that led relatives to question whether the risks could still be deemed as acceptable. The accumulation of 'red flags' led to levels of risk being viewed as unacceptable although they were previously tolerated. The 
Stevenson, M., McDowell, M. E. and Taylor, B. J. 'Concepts for communication about risk in dementia care: A review of the literature', Dementia: The International Journal of Social Research and Practice Advance Access published May 13 2016, doi: 10.1177/1471301216647542

application of risk-balancing strategies was in some instances found to return the level of risk to a level that was considered tolerable by carers.

Consistent with findings of different perceptions of risk between groups, a survey involving ranking of main precipitators of crises and of interventions to both prevent and manage crises, found that consumers (defined as people with dementia, family carers and voluntary agencies) differed from health and social care staff in their ratings of relevant risk factors in some domains. For example, physical and verbal aggression were rated as lesser risk factors by consumers than by professionals. However, there was also evidence of consistency of ranking in some areas, certain risk factors including wandering, falls, infection and family carer burden were rated highly across all groups. Notably practitioners categorised as either physical or mental health were also found to differ from each other in their responses, demonstrating how different professional groups may interpret risks and crises in different ways.

\section{Approaches to dealing with risk}

A primary aim of risk communication is to reach a shared understanding of different ideas on how risks should be approached. There were no papers examining the role of risk communication in this process. However, a number of studies examined prevalent approaches toward dealing with risk that allow for insights into how different groups deal with risk and variations in preferred approaches.

Acceptable and reasonable risk taking. A small number of papers found that carer's concepts of acceptable or reasonable risk differed between carers and professionals. Different thresholds of acceptability were underpinned by different responsibilities; for example, professionals were bound by legal aspects of their roles, such as duty to protect from harm. Personal values such as the importance of maintaining quality of life also affected subjective judgements of acceptability. The concept of acceptable or reasonable risk was explicitly referred to in three papers (Clarke et al., 2009; Cott \& Tierney, 2013; Robinson et al., 2007). Robinson et al. (2007) describe how concepts differed between family carers and professionals. Risks that were considered acceptable and tolerable to family members (e.g., wandering behaviour) were often unacceptable and potentially hazardous to professionals. The authors explain how these contrasting approaches stemmed from different perspectives and influences with professional approaches underpinned by fear of litigation while familial carers focused on quality of life for their family member. It should be noted that only three carers were involved in this study and ten professionals. Notably, individuals with mild dementia participating in this study did not refer to risks associated with wandering at all. In contrast, Clarke et al. (2009) in a survey of 46 professionals, found that participants believed family carers were more reluctant to accept any risk compared to professionals and that concepts of risk taking were closely associated with the need to maintain quality of life. Clarke et al. also acknowledged the dilemma in judging the threshold for when a particular risk reached an unacceptable level. Cott and Tierney (2013) found that concepts of acceptable risk held by 20 family carers were not static but were constantly being redefined in response to factors such as changes in abilities or behaviours. Further, familial carers defined the most unacceptable risks as risks to psychosocial wellbeing including loss of independence, reduced self-esteem and institutionalisation.

Risk-tolerance, risk-aversion and risk-balancing. There was some difference in approach to risk between the three core groups. People with dementia tended to be aware of risks but willing to tolerate them, although in some cases, apprehensions about risks led to these individuals avoiding certain situations. Professionals and family carers experienced challenges in respecting rights and needs while avoiding harm. Professionals tended to be slightly more risk-averse than family carers or people with dementia. Where evident, these 
Stevenson, M., McDowell, M. E. and Taylor, B. J. 'Concepts for communication about risk in dementia care: A review of the literature', Dementia: The International Journal of Social Research and Practice Advance Access published May 13 2016, doi: 10.1177/1471301216647542

protectionist approaches were grounded primarily in legal duties and fear of litigation, responsibilities that do not generally apply to service users.

Robinson et al. (2007) found that, in the context of a litigious society, fear of legal action among health professionals and nursing home staff, fostered approaches that minimized harm but were sometimes at odds with the rights of the person. Similarly, Clarke et al. (2011b) reported how fear of injury and consequent complaints or legal action led to risk-averse approaches in professional care. That is, risk-averse (or tolerant) approaches were steered by public and organisational culture and by personal attitudes to risk. Approaches were also influenced by legal frameworks when applicable. McDonald (2010) examined decision making of social workers in cases relating to entry to residential care following the recent implementation of the Mental Capacity Act (2005) in England and Wales (relating to decision making in the event of lack of capacity). It was found that 'risk-based' actuarial and legalistic approaches dominated practice in these cases compared to rights-based approaches. In particular, professionals experienced a dilemma in relation to decisions they felt they should make and the practical decisions they actually made.

In general, professionals sought to balance rights against risks rather than avoiding risks (Clarke et al., 2009; Clarke et al., 2011b; Cott \& Tierney, 2013; Johansson et al., 2009; Robinson et al., 2007; Waugh, 2009), a primary issue for both formal and informal dementia care. Rights of the individual included: civil liberties, societal rights, person centred care and personhood (Robinson et al., 2007); freedom of choice, maintenance of independence, quality of life and rights (Clarke et al, 2009); integrity and autonomy (Johansson et al., 2009); and independence and self-esteem (Cott \& Tierney, 2013). These rights were weighted against factors including risks, potential harm and physical injuries (Robinson et al., 2007; Johansson et al., 2009; Waugh, 2009; Cott \& Tierney, 2013);. The act of balancing rights and risks was recognised as often presenting an ethical dilemma for professionals who aim to preserve autonomy while providing appropriate care (Johansson et al., 2009, Watts et al., 1989), creating tension for staff (Waugh, 2009) and leading staff to believe they sometimes failed to provide person centred care (Robinson et al., 2007). Additional challenges for balancing rights and risks occurred when professionals and family carers ascribed different weightings to risk (Clarke et al., 2009; Waugh 2009) and when tipping factors differed between professionals and family carers (Robinson et al., 2007). Watts et al. (1989) in a study involving the case of a widower with dementia living alone who had caused a fire in his home, concluded that health professionals should be sensitive to the needs and wishes of people with dementia and make efforts to preserve the autonomy of the individual. In this regard, professionals and carers who prioritise the needs of the individual tend to adopt risk-balancing approaches (Clarke et al., $2011 \mathrm{~b})$. The practice of balancing risks aligns with risk-tolerant as opposed to risk-averse approaches in professional dementia care.

In contrast to professionals, family carers were generally found to be more tolerant of risks. However, perspectives differed according to whose perspective was being sought: Clarke et al. (2009) reported that professionals described carers as being more risk-averse and protectionist than were professionals. Carers were perceived to more tolerant as a result of more detailed knowledge of the individual in contrast to the medical knowledge and field experience relied on by professionals. Clarke (2000) proposed that this prior personal knowledge meant that family caregivers were willing to tolerate behaviours and activities that they perceived to be 'normal' for the individual. Gilmour et al. (2003) even found that local knowledge of the individual with dementia in a small rural community served as a protective factor by providing informal surveillance and in some instances enabling individuals to continue behaviours that may have been viewed as problematic in other settings. When purely medical models were referenced in the literature, these were viewed as facilitating more riskaverse approaches. In one case described by Bond et al. (2002), concerns from both the spousal carer and professionals relating to lack of insight of the individual, resulted in the individual being restricted from running, a previously enjoyed and meaningful activity.

Individuals with dementia included in the studies reviewed tended to hold more risktolerant attitudes, supporting the idea that they should be permitted to take risks. However, 
Stevenson, M., McDowell, M. E. and Taylor, B. J. 'Concepts for communication about risk in dementia care: A review of the literature', Dementia: The International Journal of Social Research and Practice Advance Access published May 13 2016, doi: 10.1177/1471301216647542

risk avoidant behaviours were also evident in the literature, based on apprehensions relating to personal safety. Considered, balanced approaches to risk were apparent in some cases. Harris (2006) concluded that individuals with dementia were not only aware of the risks they faced in daily life but were willing to tolerate these risks. Rather, these 15 individuals (with early stage dementia or mild cognitive impairment) were more concerned with issues such as maintaining independence and being involved in decision making rather than focusing on the risks they encountered. Similarly 14 younger people with dementia participating in one study prioritised independence over risk and danger focused on by professionals (Beattie, DakerWhite, Gilliard, \& Means, 2004). A personal narrative written from the perspective of an individual with dementia (Morgan, 2009) acknowledged that people with dementia are surrounded by risk from the point of diagnosis but reflected that they should be supported to take risks in order to live a full life. Clarke et al. (2010), drawing on the experiences of four individuals with mild or moderate dementia, found that personal and beneficial experiences, such as purpose and maintaining a level of autonomy over decisions, justified engagement in activities that could otherwise be perceived as risky. Alternatively, in some instances people with dementia withdrew from social activities as they felt safer at home (Harris, 2006) and reported feeling "vulnerable" when going out alone (Clarke et al., 2010). Apprehensions regarding their safety therefore led to risk avoidant behaviours in some instances. A recent study by Sandberg et al. (2015) involving interviews with 12 individuals with mild to moderate dementia, found that experiences of risk as both unfamiliar and confusing (along with associated feelings of being out of control and worry), led to more effortful and careful approaches to risk in daily situations. Participants took active measures to deal with risks including making notes of when medications were taken, checking calculations several times, taking breaks or accepting assistance. These individuals reported weighing up potential benefits against negative consequences of taking risks. In some instances decisions were made not to expose selves to risk situations. Importantly participants recognised that in avoiding particular risks, they may be exposing themselves to other undesirable outcomes such as missing out on something they wanted to do.

\section{Decision making involving risk information}

Risk communication is integral to the process of informed decision making in health and social care. Understanding how individuals with dementia make decisions using risk information, as well as identifying challenges in this domain, is essential if effective modes of risk communication are to be developed. A small number of quantitative papers on decision making about risks in dementia suggest that people with dementia may appraise risk information differently from their peers without cognitive impairment. All of these studies involved computerised experiments in laboratory settings and therefore results may not generalise to judgements about actual physical safety or psychosocial risks in everyday life. However, these studies can provide insights into the potential impacts of cognitive decline on how people with dementia appraise risks.

Delazer, Sinz, Zamarian, and Benke (2007) found that participants with mild Dementia of Alzheimer's Type (DAT) shifted more frequently between safe and risky alternatives and demonstrated less consistent response patterns than controls in a gambling task that examined risk estimations. The authors concluded that such responses indicated random decision making rather than the application of learning acquired through the task to establish an advantageous strategy. However, rather than making risky and impulsive choices, DAT participants and controls chose the most conservative response equally often, suggesting that participants did not make choices based on a lack of emotional control. Two related studies found that participants with mild DAT (Sinz, Zamarian, Benke, Wenning, \& Delazer, 2008) and participants with Parkinson's Disease Dementia (Delazer et al., 2009) tended to gamble more frequently in low winning probability conditions, indicative of more risky behaviour than controls. Sinz et al. also found that DAT participants gambled less frequently under high winning conditions than controls. Associations were found between less advantageous 
Stevenson, M., McDowell, M. E. and Taylor, B. J. 'Concepts for communication about risk in dementia care: A review of the literature', Dementia: The International Journal of Social Research and Practice Advance Access published May 13 2016, doi: 10.1177/1471301216647542

decision making and measures of cognitive functioning. Predecisional information sampling (PIS) was also found to be affected in a group of participants with mild DAT (Zamarian, Benke, Brand, Djamshidian, \& Delazer, 2015). PIS refers to the process of gathering and evaluating information prior to making a decision. The study found that the participants with mild DAT gathered significantly less information than controls in the Information Sampling Task experiment, tolerated significantly higher degrees of uncertainty and were less sensitive to reward characteristics of the task.

Alternatively, $\mathrm{Ha}$ et al. (2012) assessed framing effects on risk taking and risk aversion behaviours for people with Alzheimer's disease (AD). The authors found that, contrary to the control group, $A D$ participants chose more risky options under positive frames (rewards highlighted) compared to negative frames (punishments emphasised). Further, AD participants made more risky choices across both frames, indicating greater sensitivity to framing effects in decision making.

\section{Risk communication}

Despite an extensive and systematic search no papers were found with an explicit focus on risk communication in dementia care. Two papers were sourced following consultation with experts relating to comprehension of numerical health information by people with cognitive impairment (but not dementia). Delazer, Kemmler, and Benke (2013) and Pertl et al. (2014) demonstrated that participants with cognitive impairment (but no dementia) and those with mild cognitive impairment differed from control groups in tasks involving numerical health information, such as converting percentages or understanding dosage instructions. Lower levels of cognitive functioning were found to be associated with low health numeracy in both studies. The absence of research papers on the topic of risk communication in dementia care establishes a clear gap in the research knowledge and need for studies in this domain.

\section{Discussion and conclusions}

\section{Limitations}

The absence of papers on risk communication in dementia care led to a focus on concepts of risks as underpinning communication. While conclusions from these papers can indirectly inform understanding of risk communication and lead to some recommendations for this domain, there is considerable scope for developing our understanding of risk communication in dementia care.

A systematic literature search sought to facilitate the retrieval of all relevant papers and to reduce bias in the review process. While efforts were taken to ensure the search was as methodical as possible, it is impossible to eliminate subjectivity and associated bias in the selection process. Supplementary search techniques such as hand searching of journals, author searches, reference list searches and citation searching were not applied. Grey literature, such as policy reports and local government documents on risk in dementia care, was excluded.

While types of risks mentioned in the literature were tabulated (Table 1) to enable comparison between prevalence of physical and psychosocial risks, tallying different categories of risk was not the focus of the review and therefore the synthesis is limited in establishing those risks that were of most concern in dementia care settings. While papers on decision making involving risks were included where relevant, the authors cannot be confident that the search strategy retrieved all of the papers on such 'decision making' studies as this was not a search term. A further review may wish to search explicitly for these types of papers and synthesise the findings.

Types of risk 
Stevenson, M., McDowell, M. E. and Taylor, B. J. 'Concepts for communication about risk in dementia care: A review of the literature', Dementia: The International Journal of Social Research and Practice Advance Access published May 13 2016, doi: 10.1177/1471301216647542

As illustrated in Table 1, the majority of studies emphasised daily living and direct care risks. This could be attributed to the design of the research (e.g., some studies were designed to elicit views on a particular risk area such as falls) and to the framing of questions or tools that may have influenced risks identified. In fact, professionals recognised that they often prioritised physical rather than psychological needs, not because they viewed the latter as unimportant, but because the mechanisms for assessing and managing physical risks were more comprehensive than those relating to psychological needs (Clarke et al., 2011b). These findings support recommendations from Department of Health 'Nothing Ventured, Nothing Gained' guidance proposing that approaches to risk assessment and management should extend beyond physical risks to incorporate also psychosocial aspects of risk (Manthorpe \& Moriarty, 2010). There are occasional examples of assessment tools for older people incorporating psychosocial as well as physical risks (Taylor, 2012b) although this is generally more limited in relation to dementia specifically.

\section{Perceptions and constructions of risks}

Social construction of risk. In order to reach a shared understanding of risk, all groups affected by these risks must be involved in constructing their understanding (Clarke et al., 2011a). The current review demonstrates that there remains substantial variability in the construction and perception of risk in dementia care. According to social constructionism theories, risk concepts are generated within a sociocultural context shaped by prior knowledge and discourse of various groups or 'actors', and are therefore not purely objective or static (Lupton, 1999). Risks associated with living with dementia were constructed through conversational exchanges, personal experiences and individually acquired knowledge, highlighting the importance of involving multiple stakeholders in discussions about risk (Clarke et al., 2011a, p51). Notably all of the qualitative studies exploring perceptions and approaches towards risk in the dementia context were conducted in Western Societies (North America, Northern Europe and Australia/New Zealand). Further studies exploring perspectives in other cultures would be of interest.

Perceived risk (or protective) factors identified in the literature were categorised as risks from within the individual and their dementia and risks from external sources. The former category could be interpreted as corresponding to the medical model of disability where the cause of disablement is understood as stemming from a biological condition (Blood \& Bamford, 2010; NICE-SCIE, 2007). Alternatively, the latter category could be viewed as aligning with to the social model where it is argued that it is society and the physical environment that causes individuals to experience disablement (Blood \& Bamford, 2010; Gilliard, Means, Beattie, \& Daker-White, 2005: NICE-SCIE, 2007). Overall external risk factors were identified in the literature more frequently than those stemming from the individual and their dementia suggesting that implementation of appropriate social or environmental supports may help reduce adverse outcomes while also enabling individual's with dementia to take risks when they chose to do so.

Perceptions versus actual outcomes. The research reviewed suggests a level of disconnect between perceptions of risk held by professionals and family carers and actual risk outcomes, often such that perceptions and actualities were not congruent. These findings contribute to arguments that caregiver's and professional's perceptions of risk are independent of the mathematical probabilities of these risks (Bond et al., 2002) and that risk is not treated as objective and measurable but as fluid and context dependent (Cott \& Tierney, 2013; Taylor, 2006). The incongruence between risk perceptions and the actual frequency of risk events has been reported across disciplines including in health and environment risks (e.g., natural hazards). One explanation for this phenomenon relates to work within the psychometric paradigm of risk perception where the general adult population are found to over- or underestimate risks according to different cognitive and affective characterisations of the risk 
Stevenson, M., McDowell, M. E. and Taylor, B. J. 'Concepts for communication about risk in dementia care: A review of the literature', Dementia: The International Journal of Social Research and Practice Advance Access published May 13 2016, doi: 10.1177/1471301216647542

event, such as when the risk event is associated with feelings of dread (Slovic, 1987). However, more recent work suggests that when an individual's environment is taken into consideration, people are quite accurate in judging the actual frequency of risk events and the events more likely to occur within their social environment (Benjamin, Dougan, \& Buschena, 2001; Olivola \& Sagara, 2009; Pachur, Hertwig, \& Steinmann, 2012). For these reasons, judgements about risk events should not only take into consideration people's cognitive and affective assessments of risk, but also how relevant or frequent the risk event is likely to occur within an individual's environment.

To help challenge misperceptions, one objective of risk communication in dementia care could be to compare perceptions of risk against quantified evidence. However, a primary challenge for informing the development of risk communication tools in dementia is the difficulty in quantifying risks, in particular quantifying psychosocial risks. Accordingly, building a knowledge basis for the prevalence of different risk outcomes against which to measure perceptions is needed.

Care crises and risk. The need for decision making in relation to dementia care is often triggered by crisis or indication of impending crisis. Carers may face various options in relation to how they respond to these crises. Clear communication about the risks and benefits of different options by professionals is required to support carers facing these decisions as well as involving individuals with dementia in the process.

The concept of 'crisis' or critical stages in relation to dementia can have diverse meanings, as illustrated by the four papers in this review that explicitly referred to the concept. Crisis often implies a change of behaviour or situation, in this context commonly relating a decline in health or functional skills. However the concept of 'crisis' also embodies the concept of a difficulty or danger where an important or difficult decision must be made ("Crisis," 2010). A crisis is in essence a turning point and the decision required may be conceptualised as involving a threshold that has been crossed in some way, in common with themes arising in elder care more generally (Taylor \& Donnelly, 2006) and in other domains of health and social care (e.g. Taylor \& Killick, 2013). From the perspective of risk, the situation might be conceptualised in terms of signal detection theory (Taylor, 2012a) where the 'signal' of a critical point being reached must be detected amidst the 'noise' generated by apparently similar situations that are not in fact at the same level of crisis. For Buri and Dawson (2000) the threshold is between order and chaos in family life; the point at which family functioning ceases to be tolerable for at least one key family member providing care and nurture to one or more other, family members. The difficulty - perhaps impossibility - of measuring this crisis point on any simple scale is underlined by Waugh (2009). It is precisely in the complex dynamic interplay between risk factors that the no-longer-tolerable critical threshold is reached (MacNeil Vroomen, Bosmans, van Hout, \& de Rooij., 2013) and a decision must be made. One noteworthy common feature in the papers is that the stress - and hence crisis - is often focused on the capacity of the family carer to continue to provide essential care, in accord with the main focus of the homeostatic model developed by MacNeil Vroomen et al. (2013) and as illustrated in the study by Cott and Tierney (2013).

\section{Approaches towards risk}

When it comes to approaches towards risk in dementia care, individuals have different views and tolerance levels. In the present review, balanced approaches were often discussed, where a certain degree of risk was considered to be acceptable. When risk-averse approaches were discussed, these tended to be underpinned by legal responsibilities and fear of litigation in professional practice, and purely medical constructions of dementia fostered more protectionist approaches. In contrast, risk-tolerant approaches were often grounded in personcentred, right's based ideologies, and related to greater knowledge of the individual. In some instances, risk-taking was considered justified when personal benefits were to be experienced. 
Stevenson, M., McDowell, M. E. and Taylor, B. J. 'Concepts for communication about risk in dementia care: A review of the literature', Dementia: The International Journal of Social Research and Practice Advance Access published May 13 2016, doi: 10.1177/1471301216647542

The concept of an acceptable risk relates to determining "how safe is safe enough" (Fischhoff, Slovic, Lichtenstein, Read, \& Combs, 1978) and involves the trade-off between the risks and benefits associated with an activity. Möller (2012) adds that this is not a purely quantitative process but also necessitates consideration of ethical issues such as agency and rights. As reviewed, in dementia care the acceptability of risk was often determined through a person centred process of balancing rights and needs of the individual against risks and was a core theme identified in both formal and informal care. While this approach could be seen as aligning with an attitude towards positive risk taking in that the benefits of risk-taking were recognised (e.g., preserving rights and needs), the emphasis on balancing these benefits against the harms associated with taking the risk as opposed to harms in not taking the risk was evident. Establishing effective methods of communicating risks and benefits of different care options, applying the principles of positive risk taking (Manthorpe \& Moriarty, 2010; Morgan, 2004; Morgan \& Williamson, 2014), will support individuals to take more balanced approaches.

Risk communication ultimately plays a key role with respect to how decisions are made about risk in dementia care. Carson and Bain (2008) argue that approaches to risk taking should be judged not solely on the basis of outcomes, but on the quality of the decision-making process, including the risk communication element of this process. Further research on effective risk communication in dementia care is needed to inform this process.

\section{Decision making involving risk information}

There is an intrinsic link between risk and decision making in dementia care. Understanding the decision making abilities of individuals with dementia and the potential challenges experienced in this domain is of core importance if this group are to be adequately supported to make choices regarding their care. However, the focus of work on risks and decisionmaking in dementia primarily relate to the exploration of how cognitive impairments affect choices involving risks or probabilities in laboratory settings. While these studies suggest that people with dementia make more risky choices or have greater difficulty computing probabilities compared to people without dementia, there is a clear lack of studies evaluating how these differences translate to actual choices involving real risk situations. It is unclear whether these differences actually translate to poor decision-making in the real world or whether they may in fact lead to more adaptive decisions, particularly given that individuals with dementia are faced with a changing environment where normal (non-risky) behaviours can become risky. Further, risk taking in one domain does not necessarily transfer to others (Blais \& Weber, 2006; Rolison, Hanoch, Wood, \& Liu, 2013).

\section{Implications for risk communication}

Findings from research on decision making and risk in dementia support the importance of presenting information in a clear, transparent manner, developing more appropriate ways to present numeric probability information and being more conscious of framing effects. Supporting individuals in gathering and evaluating information at the predecisional stage is also imperative. Participants with cognitive impairment (but not dementia) were found to demonstrate lower health numeracy in two studies. We might expect this effect to be exacerbated for individuals with dementia. Low health numeracy has been associated with poorer comprehension of risks (Reyna, Nelson, Han, \& Dieckmann, 2009) and avoidance of involvement in shared decision making (Galesic \& Garcia-Retamero, 2011). Research into more effective means of presenting numeric health information to people with dementia should therefore be developed. These studies emphasise the importance of providing adequate support to enable individuals with dementia to understand health risk information (Pertl et al., 2014). However, the lack of studies evaluating risk communication or how people with dementia understand risks when communicated using different risk presentation strategies limits how work on risky choices can be used to inform people with dementia or to improve 
Stevenson, M., McDowell, M. E. and Taylor, B. J. 'Concepts for communication about risk in dementia care: A review of the literature', Dementia: The International Journal of Social Research and Practice Advance Access published May 13 2016, doi: 10.1177/1471301216647542

risk comprehension. Further research on how people with dementia understand health and social care risk information when presented in different formats is recommended.

\section{Conclusions}

Differences in concepts of and approaches towards risk both within and between groups were evident across the literature. These conceptualisations in turn are often formed through different experiences and perceptual bases. These variations in perspectives highlight the importance of communicating between all stakeholders when making care decisions involving risk. While different responses are not necessarily maladaptive, they do highlight the importance of communicating information about risks in a transparent and comprehensible way to support informed decision making. The absence of primary research papers on the topic of risk communication in dementia care warrants research in this field. Establishing a quantified knowledge base of risk outcomes in dementia care across a range of settings and risk categories would be beneficial to support the development of the most effective health and social care policies and practices.

\section{Acknowledgements}

The Authors would like to thank Joanne Knox, Subject Librarian at Ulster University for her support with the literature search for this review.

\section{Funding acknowledgements}

This study was carried out as part of a Risk Communication in Dementia grant funded by the Health and Social Care Research and Development Division, Public Health Agency in Northern Ireland and Atlantic Philanthropies. This support is gratefully acknowledged.

\section{Declaration of conflicting interests}

The Authors declare that there is no conflict of interest. 
Stevenson, M., McDowell, M. E. and Taylor, B. J. 'Concepts for communication about risk in dementia care: A review of the literature', Dementia: The International Journal of Social Research and Practice Advance Access published May 13 2016, doi: 10.1177/1471301216647542

\section{References ("papers meeting inclusion criteria for review)}

${ }^{*}$ Adams, T. (2001). The social construction of risk by community psychiatric nurses and family carers for people with dementia. Health, Risk \& Society, 3, 307-319.

Adams, T., \& Gardiner, P. (2005). Communication and interaction within dementia care triads developing a theory for relationship-centred care. Dementia: The International Journal of Social Research and Practice, 4, 185-205.

Adler, G., Rottunda, S., \& Dysken, M. (2005). The older driver with dementia: An updated literature review. Journal of Safety Research, 36, 399-407.

Alaszewski, A. (2005). A person-centred approach to communicating risk. PLoS Medicine, 2(2), e41. doi:10.1371/journal.pubmed.0020041

Alzheimer Europe. (2009). Respect for autonomy. Retrieved from http://www.alzheimereurope.org/Ethics/Definitions-and-approaches/The-four-common-bioethicalprinciples/Respect-for-autonomy

Alzheimer's Society. (2014). Factsheet: What is Dementia? Retrieved from http://www.alzheimers.org.uk/site/scripts/download_info.php?filelD=1754

*Bailey, C., Clarke, C., L., Gibb, C., Haining, S., Wilkinson, H., \& Tiplady, S. (2013). Risky and resilient life with dementia: Review of and reflections on the literature. Health, Risk \& Society, 15, 390-401.

*Beattie A, Daker-White G, Gilliard J., \& Means R. (2004). 'How can they tell?': A qualitative study of the views of younger people about their dementia and dementia care services. Health \& Social Care in the Community, 12, 359-368.

*Beattie, A., Daker-White, G., Gilliard, J., \& Means, R. (2005). 'They don't quite fit the way we organise our services': Results from a UK field study of marginalised groups and dementia care. Disability \& Society, 20, 67-80.

Benjamin, D, K., Dougan, W, R., \& Buschena, D. (2001). Individuals' estimates of the risks of death: Part II -New evidence. Journal of risk and uncertainty 22, 35-57.

Blais, A., \& Weber, E. U. (2006). A domain-specific risk-taking (DOSPERT) scale for adult populations. Judgment and Decision Making, 1, 33-47.

Blood, I. \& Bamford, S. M. (2010) Equality and Diversity and Older People with High Support Needs. York: Joseph Rowntree Foundation. Retrieved from http://www.jrf.org.uk/sites/files/jrf/supporting-older-people-full.pdf

Bodemer, N., \& Gaissmaier, W. (2012). Risk communication in health. In Roeser, S., Hillerbrand, R., Sandin, P., \& Peterson, M. (Eds.), Handbook of Risk Theory (pp. 621660). Springer: Netherlands.

*Bond, J., Corner, L., Lilley, A., \& Ellwood, C. (2002). Medicalization of insight and caregivers' responses to risk in dementia. Dementia: The International Journal of Social Research and Practice, 1, 313-328.

*Buri, H., \& Dawson, P. (2000). Caring for a relative with dementia: A theoretical model of coping with fall risk. Health, Risk \& Society, 2, 283-293.

Caddell, L. S., \& Clare, L. (2010). The impact of dementia on self and identity: A systematic review. Clinical Psychology Review, 30, 113-126.

Carson, D., \& Bain, A. (2008). Professional risk and working with people: Decision-making in health, social care and criminal justice. London: Jessica Kingsley.

Cipriani, G., Lucetti, C., Nuti, A., \& Danti, S. (2014). Wandering and dementia. Psychogeriatrics, 14, 135-142.

${ }^{*}$ Clarke, C. L. (2000). Risk: Constructing care and care environments in dementia. Health, Risk \& Society, 2, 83-93. 
Stevenson, M., McDowell, M. E. and Taylor, B. J. 'Concepts for communication about risk in dementia care: A review of the literature', Dementia: The International Journal of Social Research and Practice Advance Access published May 13 2016, doi: 10.1177/1471301216647542

*Clarke, C. L., Gibb, C. E., Keady, J., Luce, A., Wilkinson, H., Williams, L., \& Cook, A. (2009). Risk management dilemmas in dementia care: An organizational survey in three UK countries. International Journal of Older People Nursing, 4, 89-96.

${ }^{*}$ Clarke, C. L., Keady, J., Wilkinson, H., Gibb, C. E., Luce, A., Cook, A., \& Williams, L. (2010). Dementia and risk: Contested territories of everyday life. Journal of Nursing and Healthcare of Chronic Illness, 2, 102-112.

*Clarke, C. L., Wilcockson, J., Gibb, C. E., Keady, J., Wilkinson, H., \& Luce, A. (2011b). Reframing risk management in dementia care through collaborative learning. Health \& Social Care in the Community, 19, 23-32.

Clarke, C. L., Wilkinson, H., Keady, J., \& Gibb, C. E. (2011a). Risk assessment and management for living well with dementia. London: Jessica Kingsley Publishers.

Compton, S. A., Flanagan, P., \& Gregg, W. (1997). Elder abuse in people with dementia in Northern Ireland: Prevalence and predictors in cases referred to a psychiatry of old age service. International Journal of Geriatric Psychiatry, 12, 632-635.

${ }^{*}$ Cott, C. A., \& Tierney, M. C. (2013). Acceptable and unacceptable risk: Balancing everyday risk by family members of older cognitively impaired adults who live alone. Health, Risk \& Society, 15, 402-415.

Crisis. (2010). In Oxford English online dictionary (3rd ed.). Retrieved from http://www.oxforddictionaries.com/definition/english/crisis

*Delazer, M., Kemmler, G., \& Benke, T. (2013). Health numeracy and cognitive decline in advanced age. Aging, Neuropsychology, and Cognition, 20, 639-659.

*Delazer, M., Sinz, H., Zamarian, L., \& Benke, T. (2007). Decision-making with explicit and stable rules in mild Alzheimer's disease. Neuropsychologia, 45, 1632-1641.

*Delazer, M., Sinz, H., Zamarian, L., Stockner, H., Seppi, K., Wenning, G. K., ...Poewe, W. (2009). Decision making under risk and under ambiguity in Parkinson's disease. Neuropsychologia, 47, 1901-1908.

Douglas, A., Letts, L., \& Richardson, J. (2011). A systematic review of accidental injury from fire, wandering and medication self-administration errors for older adults with and without dementia. Archives of Gerontology and Geriatrics, 52, e1-e10. doi:10.1016/j.archger.2010.02.014

Edwards, A., \& Elwyn, G. (2001). Understanding risk and lessons for clinical risk communication about treatment preferences. Quality in health care, 10(Suppl. 1), i9-i13. doi:10.1136/qhc/0100009

Fetherstonhaugh, D., Tarzia, L., \& Nay, R. (2013). Being central to decision making means I am still here!: The essence of decision making for people with dementia. Journal of Aging Studies, 27, 143-150.

Fischhoff, B., Slovic, P., Lichtenstein, S., Read, S., \& Combs, B. (1978). How safe is safe enough? A psychometric study of attitudes towards technological risks and benefits. Policy Sciences, 9, 127-152.

Flanagan, N. M. (2011). Driving and dementia. Journal of Gerontological Nursing, 37(8), 1013.

Galesic, M., \& Garcia-Retamero, R. (2011). Do low-numeracy people avoid shared decision making? Health Psychology, 30, 336-341.

Gilliard, J., Means, R., Beattie, A., \& Daker-White, G. (2005). Dementia care in England and the social model of disability: Lessons and issues. Dementia: The International Journal of Social Research and Practice, 4, 571-586.

*Gilmour, H., Gibson, F., \& Campbell, J. (2003). Living alone with dementia: A case study approach to understanding risk. Dementia: The International Journal of Social Research and Practice, 2, 403-420. 
Stevenson, M., McDowell, M. E. and Taylor, B. J. 'Concepts for communication about risk in dementia care: A review of the literature', Dementia: The International Journal of Social Research and Practice Advance Access published May 13 2016, doi: 10.1177/1471301216647542

*Ha, J., Kim, E. J., Lim, S., Shin, D. W., Kang, Y. J., Bae, S. M., Yoon, H.Y., \& Oh, K. S. (2012). Altered risk-aversion and risk-taking behaviour in patients with Alzheimer's disease. Psychogeriatrics: The Official Journal of the Japanese Psychogeriatric Society, 12, 151158.

*Harris, P. B. (2006). The experience of living alone with early stage Alzheimer's disease: What are the person's concerns? Alzheimer's Care Today, 7, 84-94.

*Henry, J. D., Thompson, C., Ruffman, T., Leslie, F., Withall, A., Sachdev, P., \& Brodaty, H. (2009). Threat perception in mild cognitive impairment and early dementia. The Journals of Gerontology: Series B: Psychological Sciences and Social Sciences, 64B, 603-607.

Holmen, K., Ericsson, K., \& Winblad, B. (1999). Quality of life among the elderly-state of mood and loneliness in two selected groups. Scandinavian Journal of Caring Sciences, 13, 9195.

*Horvath, K. J., Hurley, A. C., Duffy, M. E., Gauthier, M. A., Harvey, R. M., Trudeau, S. A., Cipolloni, P.B., \& Smith, S. J. (2005). Caregiver competence to prevent home injury to the care recipient with dementia. Rehabilitation Nursing, 30, 189-196.

*Johansson, I., Bachrach-Lindström, M., Struksnes, S., \& Hedelin, B. (2009). Balancing integrity vs. risk of falling: Nurses' experiences of caring for elderly people with dementia in nursing homes. Journal of Research in Nursing, 14, 61-73.

Kröpelin, T. F., Neyens, J. C. L., Halfens, R. J. G., Kempen, G. I. J. M., \& Hamers, J. P. H. (2013). Fall determinants in older long-term care residents with dementia: A systematic review. International Psychogeriatrics, 25, 549-563.

*Lach, H. W., Thomas Reed, A., Smith, L. J., \& Carr, D. B. (1995). Alzheimer's disease: Assessing safety problems in the home: While many caregivers are practicing some form of safety precautions, they may not be aware of all of their options or the best way to prevent accidents. Geriatric Nursing, 16, 160-164.

*Ledgerd, R., Hoe, J., Hoare, Z., Devine, M., Toot, S., Challis, D., \& Orrell, M. (2015). Identifying the causes, prevention and management of crises in dementia. An online survey of stakeholders. International Journal of Geriatric Psychiatry. Advance online publication. doi: 10.1002/gps.4371

Lupton, D. (1999). Risk. Abingdon: Routledge.

MacNeil Vroomen, J., Bosmans, J. E., van Hout, H. P., \& de Rooij, S. E. (2013). Reviewing the definition of crisis in dementia care. BMC Geriatrics, 13, 10. doi:10.1186/1471-231813-10.

Manthorpe, J., \& Moriarty, J. (2010). Nothing ventured, nothing gained: Risk guidance for people with dementia. London: Department of Health. Retrieved from https://www.gov.uk/government/publications/nothing-ventured-nothing-gained-riskguidance-for-people-with-dementia

*McDonald, A. (2010). The impact of the 2005 mental capacity act on social workers' decision making and approaches to the assessment of risk. British Journal of Social Work, 40, $1229-1246$.

Möller, N. (2012). The Concepts of Risk and Safety. In Roeser, S., Hillerbrand, R., Sandin, P. \& Peterson, M. (Eds.), Handbook of risk theory: Epistemology, decision theory, ethics, and social implications of risk (pp. 55-85). London: Springer.

*Morgan, K. (2009). Risks of living with Alzheimer's disease: A personal view. The Journal of Adult Protection, 11(3), 26-29.

Morgan, S. (2004). Positive risk-taking: An idea whose time has come. Health Care Risk Report, 10, 18-19. Retrieved from http://static1.1.sqspcdn.com/static/f/586382/9538512/1290507680737/OpenMindPositiveRiskTaking.pdf?token=0sIOi\%2FrjHxlfIScnjhbMvIMOhQE\%3D 
Stevenson, M., McDowell, M. E. and Taylor, B. J. 'Concepts for communication about risk in dementia care: A review of the literature', Dementia: The International Journal of Social Research and Practice Advance Access published May 13 2016, doi: 10.1177/1471301216647542

Morgan, S., \& Williamson, T. (2014). How can 'positive risk-taking' help build dementia-friendly communities? York: Joseph Rowntree Foundation. Retrieved from http://www.jrf.org.uk/sites/files/jrf/Positive-risk-taking-dementia-summary.pdf

Moyle, W., Kellett, U., Ballantyne, A., \& Gracia, N. (2011). Dementia and loneliness: An Australian perspective. Journal of Clinical Nursing, 20, 1445-1453.

Muir, S. W., Gopaul, K., \& Odasso, M. M. M. (2012). The role of cognitive impairment in fall risk among older adults: A systematic review and meta-analysis. Age and Ageing, 41, 299-308.

National Institute for Health and Clinical Excellence \& Social Care Institute for Excellence. (2007). Dementia: The NICE-SCIE guideline on supporting people with dementia and their carers in health and social care. Leicester \& London: The British Psychological Society \& The Royal College of Psychiatrists. Retrieved from http://www.ncbi.nlm.nih.gov/books/NBK55459/pdf/TOC.pdf

Olivola, C. Y., \& Sagara, N. (2009). Distributions of observed death tolls govern sensitivity to human fatalities. Proceedings of the National Academy of Sciences of the United States of America, 52, 22151-22156.

Österholm, J., \& Hydén, L. (2014). Citizenship as practice: Handling communication problems in encounters between persons with dementia and social workers. Dementia: The International Journal of Social Research and Practice. Advance online publication. doi: $10.1177 / 1471301214563959$

*Oyebode, J. R., Bradley, P., \& Allen, J. L. (2013). Relatives' experiences of frontal-variant frontotemporal dementia. Qualitative Health Research, 23, 156-166.

Pachur, T., Hertwig, R., \& Steinmann, F. (2012). How do people judge risks: Availability heuristic, affect heuristic, or both? Journal of Experimental Psychology: Applied, 18, 314330.

*Pertl, M. T., Benke, T., Zamarian, L., Martini, C., Bodner, T., Karner, E., \& Delazer, M. (2014). Do patients with mild cognitive impairment understand numerical health information? Journal of Alzheimer's Disease, 40, 531-540.

Prince, M., Wimo, A., Guerchet, M., Ali., G. C., Wu., Y. T., \& Prina, M. (2015). World Alzheimer Report 2015. The global impact of dementia: An analysis of prevalence, incidence, costs and trends. London: Alzheimer's Disease International. Retrieved from http://www.alz.co.uk/research/WorldAlzheimerReport2015.pdf

Preferred Reporting Items for Systematic Reviews and Meta-Analyses: the PRISMA statement checklist (2009). Retrieved from http://www.prisma-statement.org/2.1.2\%20\%20PRISMA\%202009\%20Checklist.pdf

Reyna, V. F., Nelson, W. L., Han, P. K., \& Dieckmann, N. F. (2009). How numeracy influences risk comprehension and medical decision making. Psychological Bulletin, 135, 943-973.

*Robinson, L., Hutchings, D., Corner, L., Finch, T., Hughes, J., Brittain, K., \& Bond, J. (2007). Balancing rights and risks: Conflicting perspectives in the management of wandering in dementia. Health, Risk \& Society, 9, 389-406.

Rolison, J. J., Hanoch, Y., Wood, S., \& Liu, P.J. (2013). Risk-taking differences across the adult life span: A question of age and domain. The Journals of Gerontology, Series B: Psychological Sciences and Social Sciences, 69, 870-880.

* Sandberg, L., Rosenberg, L., Sandman, P. O., \& Borell, L. (2015). Risks in situations that are experienced as unfamiliar and confusing: The perspective of persons with dementia. Dementia: The International Journal of Social Research and Practice. Advance online publication. doi: 1471301215603836

Selwood, A., \& Cooper, C. (2009). Abuse of people with dementia. Reviews in Clinical Gerontology, 19, 35-43. 
Stevenson, M., McDowell, M. E. and Taylor, B. J. 'Concepts for communication about risk in dementia care: A review of the literature', Dementia: The International Journal of Social Research and Practice Advance Access published May 13 2016, doi: 10.1177/1471301216647542

*Sinz, H., Zamarian, L., Benke, T., Wenning, G. K., \& Delazer, M. (2008). Impact of ambiguity and risk on decision making in mild Alzheimer's disease. Neuropsychologia, 46, 20432055.

Slovic, P. (1987). Perception of risk. Science, 236, 280-285.

Sosa-Ortiz, A. L., Acosta-Castillo, I., \& Prince, M. J. (2012). Epidemiology of dementias and Alzheimer's disease. Archives of Medical Research, 43, 600-608.

Stacey, D., Légaré, F., Col, N. F., Bennett, C. L., Barry, M. J., Eden, K. B., ...Thomson, R. (2014). Decision aids for people facing health treatment or screening decisions. The Cochrane Database of Systematic Reviews, 1(1), CD001431. doi: 10.1002/14651858.CD001431.pub4.

Stevenson, M., Taylor, B. J., \& Knox, J. (in press). Risk in dementia care: Searching for the evidence. Health, Risk \& Society. doi: 10.1080/13698575.2015.1119256

Taylor, B.J. (2006). Risk management paradigms in health and social services for professional decision making on the long-term care of older people. British Journal of Social Work, 36, 1411-1429.

Taylor, B. J. (2012a). Models for professional judgement in social work. European Journal of Social Work, 15, 546-562.

Taylor, B. J. (2012b) Developing an integrated assessment tool for the health and social care of older people. British Journal of Social Work, 42, 1293-1314.

Taylor, B.J. (2013). Professional Decision Making and Risk in Social Work (2 ${ }^{\text {nd }}$ ed.). London: Sage.

Taylor, B. J., \& Donnelly, M. (2006). Professional perspectives on decision making about the long-term care of older people. British Journal of Social Work, 36, 807-826.

Taylor, B. J., \& Killick, C. J. (2013). Threshold decisions in child protection: Systematic narrative review of theoretical models used in empirical studies (conference abstract). Medical Decision Making, 33, E145-E203. doi: 10.1177/0272989X12455402

${ }^{*}$ Thom, K. M., \& Blair, S. E. E. (1998). Risk in dementia-assessment and management: A literature review. The British Journal of Occupational Therapy, 61, 441-447.

'Tsunaka, M., \& Chung, J. C. (2012). Care-givers' perspectives of occupational engagement of persons with dementia. Ageing and Society, 32, 543-560.

*Tuokko, H., MacCourt, P., \& Heath, Y. (1999). Home alone with dementia. Aging \& Mental Health, 3, 21-27.

*Walker, A. E., Livingston, G., Cooper, C. A., Katona, C. L. E., \& Kitchen, G. L. (2006). Caregivers' experience of risk in dementia: The LASER-AD study. Aging \& Mental Health, 10, 532-538.

*Watts, D. T., Cassel, C. K, \& Howell, T. (1989). Dangerous behavior in a demented patient. Preserving autonomy in a patient with diminished competence. Journal of the American Geriatrics Society, 37, 658-662.

*Waugh, F. (2009). Where does risk feature in community care practice with older people with dementia who live alone? Dementia: The International Journal of Social Research and Practice, 8, 205-222.

While, C., Duane, F., Beanland, C., \& Koch, S. (2013). Medication management: The perspectives of people with dementia and family carers. Dementia: The International Journal of Social Research and Practice, 12, 734-750.

Wimo, A., Jönsson, L., Bond, J., Prince, M., Winblad, B., \& International, A. D. (2013). The worldwide economic impact of dementia 2010. Alzheimer's \& Dementia, 9, 1-11.

Wimo, A., Winblad, B., \& Jönsson, L. (2010). The worldwide societal costs of dementia: Estimates for 2009. Alzheimer's \& Dementia, 6, 98-103. 
Stevenson, M., McDowell, M. E. and Taylor, B. J. 'Concepts for communication about risk in dementia care: A review of the literature', Dementia: The International Journal of Social Research and Practice Advance Access published May 13 2016, doi: 10.1177/1471301216647542

World Health Organisation. (1993). The ICD-10 classification of mental and behavioural disorders. Diagnostic criteria for research. WHO: Geneva. Retrieved from http://www.who.int/classifications/icd/en/bluebook.pdf

World Health Organisation. (2015). Dementia. Factsheet No.362. Retrieved from http://www.who.int/mediacentre/factsheets/fs362/en/

Wortmann, M. (2012). Dementia: A global health priority-highlights from an ADI and world health organization report. Alzheimer's Research \& Therapy, 4, 40. doi:10.1186/alzrt143

*Zamarian, L., Benke, T., Brand, M., Djamshidian, A., \& Delazer, M. (2015). Impaired information sampling in mild dementia of Alzheimer's type but not in healthy aging. Neuropsychology, 29, 353-367.

\section{Author biographies}

Mabel Stevenson is a Research Assistant at Ulster University. Her research focuses on the topic of risk communication in dementia care. Mabel has previously been employed in the health \& social care and voluntary sectors and has experience of working directly with individuals with dementia and their families. She is part of the programme group for the British Society of Gerontology in Northern Ireland.

Michelle E McDowell is a researcher at the Harding Center for Risk Literacy, at the Max Planck Institute for Human Development, Berlin. She is interested in improving informed decision making in health and in promoting the transparent communication of health risk information to patients and professionals. Her recent research has been on the development of simple risk communication tools and visualisations to facilitate the communication and comprehension of health risks.

Brian J Taylor is Professor of Social Work at Ulster University, Northern Ireland, having previously worked in practice, management, training and organisation development. Brian leads a research cluster on Decision, Assessment, Risk and Evidence Studies, and has published widely on these topics. He is Chief Investigator for the three-year study of Risk Communication in Dementia on which this paper is based. 